\title{
How well do nursing staff assess the wellbeing of nursing home residents? An explorative study of using single-question scales
}

\author{
Noortje Kloos $^{1 \star}$ (D), Constance H. C. Drossaert ${ }^{1}$, Ernst T. Bohlmeijer ${ }^{1}$ and Gerben J. Westerhof ${ }^{1}$ \\ ${ }^{1}$ Department of Psychology, Health and Technology, Centre for eHealth and Wellbeing Research, \\ University of Twente, Enschede, The Netherlands \\ ${ }^{\star}$ Corresponding author. Email: n.kloos@utwente.nl
}

(Accepted 18 August 2020; first published online 22 September 2020)

\begin{abstract}
Person-centred care requires improved documentation of nursing home resident wellbeing, e.g. by nursing staff proxy assessments. Previous studies mainly focused on proxy self-report agreement of quality of life of people with dementia, using lengthy questionnaires. This is the first study to investigate how well nursing staff assess residents' wellbeing after training, using a single-question assessment method of happiness and engagement. We conducted a cross-sectional mixed-method study, including proxy assessments from 49 nursing staff, and self-reports from 49 nursing home residents without dementia (mean age 85). We explored agreement between colleagues, and between proxy assessments and self-reports, and potential nursing staff characteristics associated to this (age, experience, hours worked per week). Brief written motivations were evaluated on nursing staffs' understanding of the happiness and engagement concepts. The results showed low agreement between colleagues, and low agreement between proxy assessments and self-reports. Nursing staff assessed happiness and engagement substantially higher than residents' self-reports. Hours worked per week was related to happiness proxy assessments, but none of the included nursing staff characteristics were related to proxy self-report agreement. Nursing staff interpreted the concepts in diverse ways. Overestimating resident wellbeing when using this single-assessment method may undermine subsequent efforts to improve wellbeing. We could not identify which nursing staff could best provide wellbeing assessments. For now, proxy wellbeing assessments should always be combined with regular self-reports whenever possible.
\end{abstract}

Keywords: happiness; engagement; quality of life; long-term care; proxy assessment; professional care-giver

\section{Introduction}

Nursing homes are striving to become more person-centred (Koren, 2010). When providing person-centred care (PCC), nursing staff connect with older adults as unique individuals with their own personal experiences and preferences, rather

(C) The Author(s), 2020. Published by Cambridge University Press on behalf of Ageing \& Society. This is an Open Access article, distributed under the terms of the Creative Commons Attribution licence (http://creativecommons.org/licenses/by/ $4.0 /$ ), which permits unrestricted re-use, distribution, and reproduction in any medium, provided the original work is properly cited. 
than viewing them as patients and emphasising illness (Edvardsson et al., 2008; Edvardsson, 2015). Providing PCC can have important positive outcomes, like improved resident wellbeing (McCormack and McCance, 2010; Rathert et al., 2013). However, it can be difficult to implement PCC innovations in the highly pressured residential aged-care settings (Cooper et al., 2018). Progress towards providing PCC can be monitored by regularly assessing and documenting resident wellbeing. The current study investigates how well nursing staff are able to make assessments of resident wellbeing.

Wellbeing can be defined in various ways. According to the hedonic tradition, wellbeing is conceptualised as happiness: experiencing balanced positive and negative emotions, and being satisfied with life (Diener et al., 1999). In this tradition wellbeing is thus mostly concerned with feeling good. Second, the eudaimonic approach describes wellbeing as an active process of living well: living a complete life and realising human potentials (Ryan and Deci, 2001). The concept of engagement fits in this tradition, in which a person is absorbed in an activity, to the point of forgetting time, fatigue and everything else but the activity itself, described as an experience of flow (Csikszentmihalyi et al., 2015). A comprehensive definition of wellbeing includes both feeling good (e.g. happiness) and living well (e.g. engagement) (Keyes, 2002).

Wellbeing is seen as an important variable, however, nursing documentation is currently almost exclusively dedicated to describing physical care (Broderick and Coffey, 2013). Residents may be the most valid source of their subjective experiences of happiness and engagement, but dementia and other physical disorders can impede introspection and communication. Nursing staff have daily contact with the residents, and can alternatively provide proxy assessments of resident happiness and engagement. In general, people are able to estimate the wellbeing of others to some extent, although assessments are far from perfect (Schneider and Schimmack, 2009). In the nursing home context, some studies have examined the value of proxy assessments, but mostly for the - more broad - concept of quality of life (QoL). These studies have shown inconclusive results. Low to moderate agreement is shown between proxy-assessed and self-reported QoL (e.g. Devine et al., 2014; Usman et al., 2019), nursing staff seem to both overestimate (Kane et al., 2005) and underestimate residents' QoL (Beer et al., 2010; Griffiths et al., 2020). Especially the more subjective components of QoL may be difficult to assess by proxies (Diaz-Redondo et al., 2014), which may be most comparable to wellbeing. However, many of these QoL assessment studies included proxy assessment instruments that did not always correspond closely to those used for self-reports and were often conducted with older adults with dementia. This leaves the possibility that high discrepancies were caused by the dissimilarity between instruments or the introspective problems of the residents with dementia (Gerritsen et al., 2007; Hounsome et al., 2011). However, studies in palliative care have also shown that there is systematic overestimation of physical symptoms and underestimation of psychological wellbeing by staff in comparison to patients (Murtagh et al., 2019).

These inconclusive findings may also rise from nursing staff differing in their ability to assess the wellbeing of residents adequately. Several nursing staff usually have daily contact with a resident, and previous studies have found both sufficient (Ettema et al., 2007) and insufficient agreement between colleagues in their assessments of resident QoL (Dichter et al., 2014). An important condition for valid 
proxy assessments of resident wellbeing is that nursing staff interpret wellbeing assessment items in a similar way (Griffiths et al., 2020). Others therefore recommended provision of training in the assessment method and a manual with clear and accurate definitions of the items (Dichter et al., 2014). It is important to investigate whether sufficient agreement between colleagues and a similar interpretation of the concepts are indeed found when using such methods.

Variation between colleagues in proxy assessments would also necessitate identifying those care-givers who are best able to assess wellbeing. While a recent systematic review revealed various nursing staff characteristics that were related to how high they assessed QoL (e.g. staff distress, having a contract) (Robertson et al., 2017), few studies investigated whether such care-giver factors could also indicate how well they assessed wellbeing in comparison to self-report. Two studies found that nursing staff age, experience in working in elder-care and function were not related to the discrepancy between QoL proxy assessments and self-reports of residents with dementia (Spector and Orrell, 2006; Gräske et al., 2012). More research is needed on potential nursing staff characteristics that are related to proxy selfreport agreement for the wellbeing of residents without dementia.

Besides these issues with agreement, it can also be challenging to actually implement regular wellbeing assessments in the context of the nursing home. The instruments that are currently available for proxy assessments of QoL are often quite lengthy, and there is a need for suitable, accessible and easy-to-use measures (Hughes et al., 2019). Since excessive paperwork can be an important barrier for implementing regular wellbeing assessments in the nursing home context (Griffiths et al., 2019), we propose that short and simple methods like single questions are more suitable for regular monitoring and documentation of resident wellbeing. Single-question self-reports allow for the full expression of residents' values and preferences (Gill and Feinstein, 1994), and have been used as reliable and valid indicators for concepts such as subjective health, subjective age, QoL and life satisfaction (Gerritsen et al., 2007; Veenhoven, 2008; Westerhof et al., 2014; Usman et al., 2019).

The current study is the first to investigate how nursing staff assessments of nursing home resident wellbeing compare to self-reports after training, with a single-question assessment method of happiness and engagement. We explore (a) the level of agreement between colleagues in their proxy assessments, (b) the level of agreement between nursing staff proxy assessments and resident selfreports, (c) potential nursing staff characteristics associated with the level of agreement between proxy assessments and self-reports, and (d) how nursing staff understand the concepts of wellbeing.

\section{Methods}

\section{Sample and procedure}

This study adopted a cross-sectional mixed-methods design. Data collection was part of a training programme to assess resident wellbeing, developed for a large care organisation in the Netherlands accounting for 17 nursing homes. Two nursing homes of comparable size were included, based on voluntary registration of the 


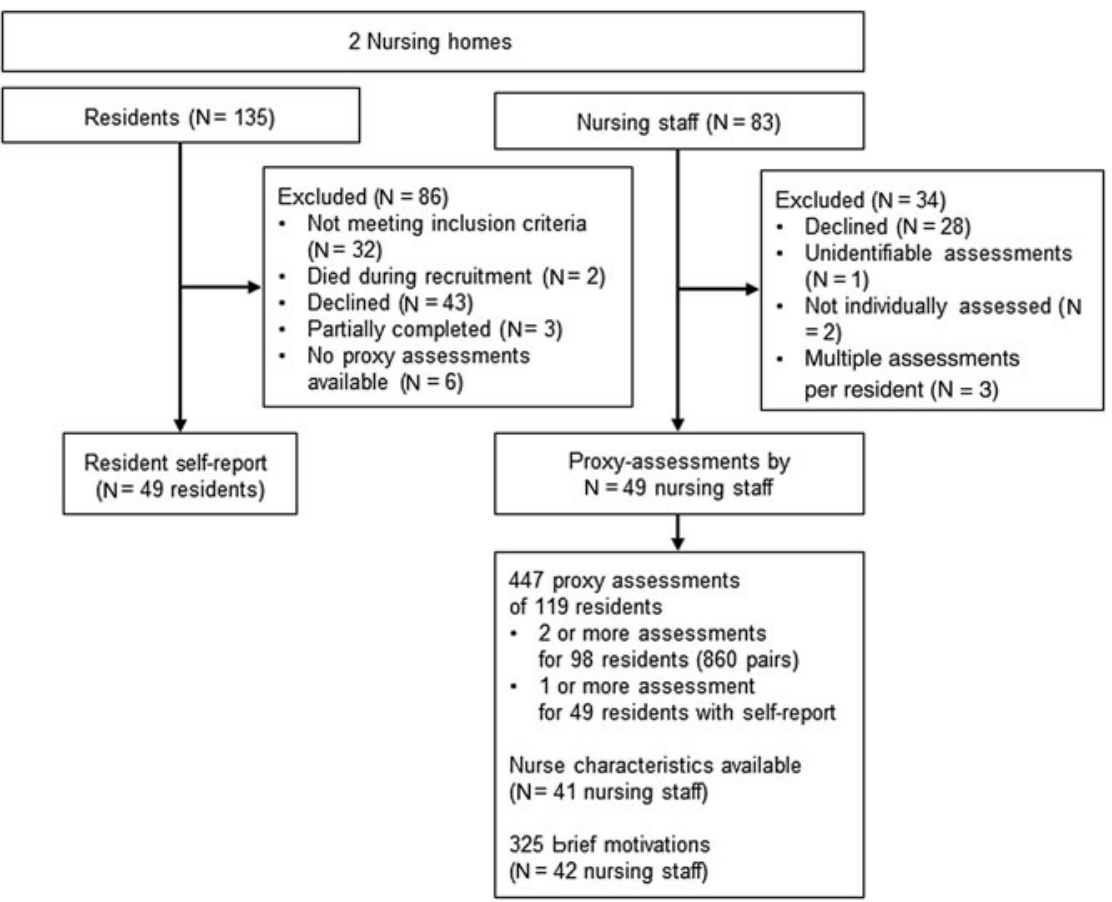

Figure 1. Flowchart of participants and available assessments.

managing directors. All eight long-term care units of these nursing homes (four each) participated in this study, each unit consisting of 12-25 physically frail residents and approximately ten nursing staff providing physical care to these residents. Figure 1 shows the flowchart of participants.

\section{Residents}

All 135 residents of the participating units received informational letters. Exclusion criteria for the study were: major hearing, speech or cognitive problems and dementia $(\mathrm{N}=32)$, as established by nursing staff. Participation was voluntary upon giving informed consent. Participation was declined by 43 older adults and the self-reports of nine residents were excluded from analyses for various reasons (Figure 1). This resulted in a final sample of 49 residents providing self-reports of their happiness and engagement, assisted by a trained member of the research team consisting of two graduated psychologists and one psychology undergraduate.

\section{Nursing staff}

All 83 nursing staff of the participating units received a mandatory training in assessing happiness and engagement, consisting of three face-to-face group meetings of two hours each. In the first session, nursing staff discussed the concepts of happiness and engagement and practised how to observe these in nursing home residents, using video fragments. In the second session, participants practised 
how to provide proxy assessments of happiness and engagement using video fragments. In the subsequent weeks, nursing staff observed the residents in their unit for two weeks and provided proxy assessments of resident happiness and engagement (see nursing staff measures). Nursing staff could then voluntarily hand in their proxy assessments for one or several residents in their unit as part of the current study. Participation was declined by 28 nursing staff, and the assessments of six nursing staff were excluded from analyses for various reasons (Figure 1). This resulted in a final sample of 49 nursing staff providing proxy assessments of one or more residents. The assessments were discussed in a third return meeting, but the current study only covers the completed and submitted assessment forms.

\section{Combinations of assessments available for analysing agreement}

In total, the nursing staff provided 447 proxy assessments relating to 119 residents (see Figure 1). Proxy assessments from two or more nursing staff (maximum eight) were available for 98 residents, resulting in 860 proxy assessment pairs available for computing the level of agreement between colleagues for happiness and engagement. Proxy assessments from one or more nursing staff (maximum eight) were available for the 49 residents who provided self-reports, resulting in 49 combinations available for computing proxy self-report agreement. Nurse characteristics were available for 41 nursing staff who provided proxy assessments for computing associations between nurse characteristics and proxy self-report agreement. Finally, 42 nursing staff provided brief motivations, resulting in 325 brief motivations available for analysing nursing staff understanding of the concepts.

\section{Nursing staff measures}

Proxy assessments of happiness and engagement.

Proxy assessments of happiness and engagement were gathered using an adapted version of the Leuven Well-being and Involvement Scale (L-WIS; Laevers, 2005). In the L-WIS, happiness and engagement are rated on two separate 1-5 scales, with higher scores indicating better wellbeing, and a question mark indicating a lack of information to make a clear assessment. This monitoring tool was originally developed for education and child care (Laevers, 2005), and adapted to include detailed descriptions of feelings and behaviours of older adults corresponding to each of the happiness and engagement assessment scores (for descriptions, see the online supplementary material).

Proxy assessments were included only when both a valid happiness and a valid engagement assessment were provided (a question mark was considered an invalid assessment). When nursing staff assigned two scores for one assessment (e.g. both 3 and 4 for wellbeing for resident A), this was coded as the mean of the two scores (e.g. 3.5). The L-WIS assessment form includes space to assign both assessments per resident (up to 25 residents), and to provide some additional qualitative information to support these assessments (i.e. brief motivations) for each resident.

\section{Nursing staff characteristics}

Demographic and work-related data (i.e. age, function, hours worked per week, experience and function) were gathered as part of another study. 


\section{Resident measurements}

Happiness

Self-reported happiness was measured using a single question that matched the L-WIS nursing staff assessment, and with two established happiness questionnaires. The single question of happiness (i.e. 'All in all, how good did you feel in the previous week including today?') was answered on a scale from $1=$ not good at all to 5 $=$ excellent. Then in line with the L-WIS, a detailed description of feelings corresponding to that score was provided (e.g. for score 5: 'I felt great, I felt relaxed, I had confidence and I thoroughly enjoyed myself). Residents indicated whether this described their happiness, or could choose another rating description when better fitting.

The established questionnaire measuring the balance of positive and negative emotions was the Dutch version of the Geriatric Depression Scale (GDS; Jongenelis et al., 2007). This scale is specifically designed for nursing home residents, measuring the presence of both positive feelings (four items, e.g. 'Do you feel happy most of the time?') and negative feelings (four items, e.g. 'Do you feel that your life is empty?'), answered with 'yes' or 'no'. A sum score is computed, with high scores indicating more depressive feelings. The scale had a reliability of $\alpha=0.86$ in the current sample.

The established questionnaire measuring life satisfaction was the Satisfaction With Life Scale (SWLS; Diener et al., 1985; Custers et al., 2010). Five items (e.g. 'I am satisfied with my life') were scored on a scale from $1=$ totally disagree to 5 = totally agree. To improve clarity, the final question was restated into a positively formulated question, without changing the content of the question. This resulted in a satisfactory item-total correlation of 0.53 . A sum score was calculated, with higher mean scores indicating greater life satisfaction. The scale has shown good psychometric properties (Pavot and Diener, 1993). In the current sample, the scale had a reliability of $\alpha=0.84$, which is higher than was found previously with the unadjusted version of the scale with older adults ( $\alpha=0.69$; Custers et al., 2010).

\section{Engagement}

Self-reported engagement was also measured using both a single question matching the L-WIS care-giver assessment, and an established engagement questionnaire. The single question of engagement (i.e. 'How often were you completely absorbed in what you did?') was answered on a scale from $1=$ rarely to $5=$ most often. Then in line with the L-WIS, a detailed description of feelings corresponding to that score was provided (e.g. for score 5: 'Most of the time, I was highly concentrated and continuously involved in an activity, which made me forget the time and I could not be distracted'). Residents indicated whether they felt this described their engagement, with the opportunity to choose another rating description when suited.

The established questionnaire measuring engagement with good construct validity and reliability was the leisure scale of the Swedish Flow Proneness Questionnaire (SFPQ; Ullén et al., 2012). However, participants indicated that this questionnaire was too difficult, which resulted in many missing values. This measure was therefore omitted during data gathering, and results are not discussed further. 


\section{Resident characteristics}

Demographic data (i.e. age, gender, marital status, number of children) and subjective health (i.e. 'How is your health generally?'; scale $1=$ poor to $5=$ excellent) were additionally self-reported. Independency of activities of daily living (ADL; i.e. bathing, clothing, mobility, toileting, continence and eating) were rated by nursing staff on a scale from $1=$ can do this without help to $4=$ needs help with all aspects of the activity, using the Katz ADL (Katz et al., 1963). Total scores range from 6 to 24, with higher scores indicating greater ADL dependency.

\section{Analysis}

Quantitative data were analysed using IBM SPSS 24, with the alpha level set to 0.05.

\section{Agreement between colleagues}

To analyse how well nursing staff assessments correspond between colleagues, the inter-rater agreement between proxy assessments was analysed. First, the proportion of exact agreement between proxy assessments was examined. For each resident, the number of matching assessments (i.e. absolute difference of 0) was divided by the total number of available assessments for that resident (Kottner and Dassen, 2008). Second, relative agreement between proxy assessments was examined, which takes into account that scores that are closer together on ordinal five-point proxy scales indicate more agreement. Krippendorff's alpha was examined, using the macro of Hayes and Krippendorff (2007), based on 1,000 bootstrapped samples.

\section{Agreement between proxy assessments and self-reports}

To analyse how well nursing staff assess wellbeing, the agreement between proxy assessments and self-reports of happiness and engagement was tested. For resident self-reports, missing data on individual items of the established self-reported happiness questionnaires $(0.6 \%)$ were replaced with the respondent's mean of that scale. Pearson correlations were computed between the single-question selfreported happiness and self-reported GDS (depressive feelings) and SWLS (life satisfaction) scores as a test of concurrent validity. Correlations $r<0.30$ are indicated as weak, $r<0.50$ moderate and $r \geq 0.50$ as strong correlations (Cohen, 1988).

For the proxy assessments, the means of all available assessments of each resident (ranging from one to eight assessments) were calculated. Pearson correlations and paired sample $t$-tests were then conducted. Furthermore, two-way random effects intra-class correlations (ICC) of absolute consistency with multiple raters were computed. ICC $\leqslant 0.50$ was indicated as poor, $0.50<$ ICC $<0.75$ as moderate, $0.75<$ ICC $<0.90$ as good and ICC $\geq 0.90$ as excellent (Koo and Li, 2016).

\section{Nurse characteristics and proxy self-report agreement}

Further, to analyse whether particular nursing staff are best able to assess resident wellbeing, the associations between nursing staff characteristics and both level of proxy assessment and proxy self-report agreement were tested. Three nursing staff characteristics were included: age, experience working in elder-care and number of working hours per week. For the level of proxy assessments, average 
assessment scores were calculated for each nursing staff, from all assessments (one to ten) that they provided. Nursing staff mean agreement with self-reports was calculated by averaging the absolute differences between proxy assessments and the corresponding residents' single-question self-reports for each nursing staff, ranging from $0=$ no discrepancy/high agreement to $4=$ high discrepancy/low agreement. Pearson correlations were examined for age and experience, and Spearman's rho correlations for the number of hours worked, in relation to average assessment scores and discrepancy scores.

\section{Nursing staff understanding of concepts}

Finally, we explored whether nursing staffs' interpretations of the concepts of happiness and engagement were in line with the definitions presented in the training and the assessment manual. An explorative qualitative analysis was conducted on the brief motivations nursing staff provided on the assessment forms. Information was first categorised as describing either happiness or engagement, based on the interpretation of the researchers. The brief motivations of 26 nursing staff were then open coded in Excel. A coding system of the happiness and engagement codes was created through deliberation between the first and the last author. Using Atlas.ti 8, each brief motivation was then assigned one happiness code and one engagement code. Finally, codes were grouped, based on three main themes of interpretation: (a) matching the definition, (b) different from definition, and (c) unknown. The content of the brief motivations that did not discuss either happiness or engagement was additionally analysed bottom-up.

\section{Results \\ Participants}

\section{Residents}

The 49 residents who completed self-reports had a mean age of 84.5 years (standard deviation $(S D)=7.0$, range $=56-100)$. Most residents were female $(66 \%)$, widowed (68\%) and had one or more children (92\%). Residents had a reasonable subjective health (mean $=2.4, \mathrm{SD}=0.6$, range $=1-4$ ) and moderate ADL dependency $($ mean $=11.1, \mathrm{SD}=4.6$, range $=6-19)$.

\section{Nursing staff}

The 49 nursing staff who provided proxy assessments had a mean age of 38.1 years $(\mathrm{SD}=12.4$, range $=18-57)$, most were female $(95 \%)$, most were licensed practical nurses (91\%) and many worked 17-24 hours per week (43\%), with on average $13.7(\mathrm{SD}=11.5)$ years of experience working in nursing home settings.

\section{Agreement between colleagues}

Table 1 shows that proxy assessments about the same resident differed on average less than one point between colleagues. Exact agreement between the proxy assessments occurred in a minority of cases, and Krippendorff's alpha showed low relative agreement. 
Table 1. Mean scores of proxy assessments and difference and agreement between colleagues

\begin{tabular}{llccc}
\hline & \multicolumn{2}{c}{ Mean values (SD) } & & \\
\cline { 2 - 3 } & Assessment & Difference & & \multicolumn{2}{c}{ Agreement } \\
\cline { 3 - 4 } & & & Exact $(\%)$ & Relative $(\alpha, 95 \% \mathrm{Cl})$ \\
\hline Happiness & $3.4(0.8)$ & $0.7(0.4)$ & 42 & $0.46(0.45-0.55)$ \\
\hline Engagement & $3.6(1.0)$ & $0.8(0.5)$ & 36 & $0.40(0.36-0.44)$ \\
\hline
\end{tabular}

Notes: $\mathrm{N}=49$ colleagues, comparing 860 proxy assessment pairs. $\mathrm{Cl}$ : confidence interval. SD: standard deviation.

\section{Agreement between proxy assessments and self-reports}

Table 2 shows happiness and engagement data for the residents who provided self-reports.

Residents reported positive happiness and engagement, with a moderate interrelation. Self-reported happiness was moderately related to life satisfaction and depressive feelings $(r=0.31, p=0.03$ and $r=-0.48, p=0.001$, respectively; not in Table 2), indicating concurrent validity. Resident demographics were not related to self-reported happiness or engagement scores (not in Table 2). Nursing staff proxy assessments of resident happiness and engagement also had positive mean scores, and were strongly interrelated.

\section{Agreement}

Moderate correlations were found between proxy assessments and self-reports for happiness, and no significant correlations for engagement. For both happiness and engagement, proxy assessments were significantly higher than resident selfreports. The intra-class correlation showed poor consistency between proxy

Table 2. Mean scores, intercorrelations and agreement between nursing staff average proxy assessments and resident self-reports

\begin{tabular}{|c|c|c|c|c|c|c|c|}
\hline & \multirow[b]{2}{*}{ Scale } & \multirow[b]{2}{*}{$\begin{array}{l}\text { Mean } \\
\text { (SD) }\end{array}$} & \multirow[b]{2}{*}{1} & \multirow[b]{2}{*}{2} & \multirow[b]{2}{*}{3} & \multicolumn{2}{|c|}{$\begin{array}{l}\text { Proxy versus } \\
\text { self-report }\end{array}$} \\
\hline & & & & & & $\begin{array}{l}\text { Paired } \\
\text { sample } t \text {-test }\end{array}$ & ICC \\
\hline \multicolumn{8}{|l|}{ Happiness: } \\
\hline 1. Self-report & $1-5$ & $3.4(1.0)$ & & & & & \\
\hline 2. Proxy assessed & $1-5$ & $3.8(0.8)$ & $0.32^{\star}$ & & & $\begin{array}{c}t(48)=3.03 \\
p=0.004\end{array}$ & $0.43^{*}$ \\
\hline \multicolumn{8}{|l|}{ Engagement: } \\
\hline 3. Self-report & $1-5$ & $3.1(1.2)$ & $0.40^{\star \star}$ & 0.09 & & & \\
\hline 4. Proxy assessed & $1-5$ & $4.0(0.8)$ & 0.18 & $0.66^{\star \star}$ & 0.12 & $\begin{array}{c}t(42)=4.93 \\
p=0.000\end{array}$ & 0.14 \\
\hline
\end{tabular}

Notes: Comparing 49 proxy self-report pairs. SD: standard deviation. ICC: intra-class correlation.

Significance levels: * $p<0.05,{ }^{* *} p<0.01$. 
Table 3. Mean scores of proxy assessments and proxy self-report discrepancy and relations with nursing staff characteristics

\begin{tabular}{|c|c|c|c|c|c|}
\hline & $\begin{array}{l}\text { Mean } \\
\text { (SD) }\end{array}$ & Range & $\begin{array}{l}\text { Age } \\
(r)\end{array}$ & $\begin{array}{l}\text { Experience } \\
(r)\end{array}$ & $\begin{array}{l}\text { Hours worked } \\
\text { per week }\left(r_{s}\right)\end{array}$ \\
\hline \multicolumn{6}{|c|}{ Proxy assessments: } \\
\hline Happiness & $3.3(0.4)$ & $2.3-4.0$ & 0.16 & 0.22 & $0.31^{*}$ \\
\hline Engagement & $3.3(0.6)$ & $1.6-5.0$ & 0.04 & 0.01 & 0.13 \\
\hline \multicolumn{6}{|l|}{$\begin{array}{l}\text { Proxy self-report } \\
\text { discrepancy: }\end{array}$} \\
\hline Happiness & $0.9(0.5)$ & $0.0-3.0$ & -0.20 & -0.17 & 0.05 \\
\hline Engagement & $1.4(0.5)$ & $0.6-3.0$ & 0.01 & 0.09 & -0.19 \\
\hline
\end{tabular}

Notes: For 41 nursing staff. SD: standard deviation. $r$ : Pearson correlation. $r_{s}$ : Spearman's rho correlation. Significance level: ${ }^{*} p<0.05$.

assessments and self-reports for happiness and no consistency for engagement. The number of available proxy assessments for each resident was not related to proxy self-report agreement (not in Table 2).

\section{Nurse characteristics and proxy self-report agreement}

For the 41 nursing staff for whom nurse characteristics were available, the average proxy assessments of happiness and engagement had similar positive mean scores, with a wider range for engagement (see Table 3). Mean discrepancy between nursing staffs' proxy assessments and resident self-reports was bigger for engagement than for happiness. Only the number of hours worked per week was (borderline significantly) related to average happiness assessments $\left(r_{s}=0.31, p=0.046\right)$, with more hours related to higher assigned happiness scores. None of the nursing staff characteristics were related to the discrepancy scores.

\section{Nursing staff understanding of concepts}

A total of 325 brief motivations were analysed qualitatively on the interpretation of happiness and engagement matching definitions of happiness and engagement presented in the training and the assessment manual.

\section{Matching}

Many brief motivations described happiness (54\%) and engagement (22\%) in line with the training and assessment manual. Some brief motivations included rather rich descriptions of situations in which happiness and engagement were experienced. Happiness was described as residents experiencing enjoyment of social contact and trips outside the nursing home, or sadness over physical problems. Engagement was only a few times described as active participation in specific activities, with focus, fascination and (lack of) concentration: 'was actively working on knitting socks'. 


\section{Different}

For happiness, very few descriptions (2\%) were not in line with the definition provided in the training, describing happiness as a personal characteristic: being a positive or negative person, rather than a state: 'is sometimes very difficult and sometimes negative'. Engagement was also described (6\%) as a personal characteristic: being an active person, rather than a state. Additionally, many motivations (13\%) merely described the attending activities, instead of the level of active participation in these activities and often (12\%) motivations described residents expressing interest in other people: 'always asks how I am doing'.

\section{Unknown}

A few times, care-givers merely used the term happiness (2\%) or engagement $(6 \%)$, without any further description.

\section{Unrelated information}

A large proportion (42\%) of brief motivations included information unrelated to happiness and engagement. About a third of these described characteristics of the residents, such as being independent, talkative and able to communicate, as well as having humour, being friendly, grateful and not wanting to complain. Another third of these brief motivations described the situation of the resident: physical problems (e.g. being tired, having pain, impairments, dementia diagnosis), social contacts and the family situation (e.g. illness of family member, divorce). Residual codes included: stimulating residents to attend (organised) activities, resident autonomy, the need for a volunteer, corrigibility, trusting others and showing variable behaviour.

\section{Discussion}

The current study investigated how well nursing staff are able to assess the wellbeing of nursing home residents, using single questions of happiness and engagement. We followed previous recommendations to provide nursing staff with training and detailed scoring manuals (Dichter et al., 2014), only included self-reports of residents without dementia, and used comparable tools for proxy assessments and selfreports. Despite these adaptations, the results showed that nursing staff assessments varied considerably between colleagues, which is in line with Dichter et al. (2014), but not with Ettema et al. (2007). Moreover, nursing staff were not sufficiently able to assess resident wellbeing, in line with previous studies showing moderate proxy self-report agreement in the general population (Schneider and Schimmack, 2009), and low to moderate relations for QoL in nursing homes (Devine et al., 2014). We found that nursing staff overestimated wellbeing compared to self-reports, which is in line with some (Kane et al., 2005) but not in line with various other studies of QoL proxy self-report agreement (e.g. Griffiths et al., 2020). Nursing staff who worked more hours tended to estimate higher resident happiness. Finally, none of the included care-giver factors were related to the discrepancy between care-giver assessments and self-reports (in line with Spector and Orrell, 2006). There may be several explanations for the current results, which are described below.

One important potential explanation for the low agreement between colleagues lies in nursing staff's varying understanding of the concepts of wellbeing. Even 
though we provided a manual with a clear and detailed definition of the concepts and nursing staff practised with video fragments, happiness and especially engagement seemed to be interpreted in diverse ways. Engagement was sometimes interpreted as having interest in others, a commonly used alternative definition of engagement in Dutch ('betrokkenheid'). Different from a recent study showing that nursing staff generally described QoL in terms of the quality of care that was provided (Robertson et al., 2020), nursing staff in the current study described happiness and engagement often as resident characteristics (e.g. being a positive or active person). Furthermore, instead of wellbeing, care-givers often described rather objective aspects, like the situation of the resident (e.g. having physical problems). These results could reflect some care-givers' difficulty with elaborating on observations in words, highlighting their unfamiliarity with discussing psycho-social aspects compared to documenting physical care (Irving et al., 2006; Murtagh et al., 2019). This is also an important issue for providing PCC, because viewing wellbeing as a stable trait or part of stable objective aspects may hamper investments towards improving wellbeing. Moreover, this indicates that instead of truly assessing whether residents were feeling good or being absorbed in activities, nursing staff may have observed different concepts.

In a similar vein, residents' understanding of the concepts may have influenced the proxy self-report agreement results (Bulamu et al., 2015). The validity of evaluating nursing staff assessments through comparison with residents' self-reports depends on residents' ability to assess their own wellbeing (e.g. Kane et al., 2005). Evidence for the validity of the single question of self-reported happiness was provided by the moderate relations with questionnaires of depressive feelings and life satisfaction. However, comparable to the qualitative analysis we conducted on nursing staffs' understanding of the wellbeing concepts, residents' interpretation of the single questions should be further investigated (Griffiths et al., 2020), for example through cognitive interviewing.

Furthermore, even though we trained nursing staff, assessing subjective experiences of resident wellbeing may still have been too difficult (Diaz-Redondo et al., 2014), which could explain the low proxy self-report agreement found in the current study. Combining and weighting several observations to reach an overall indication of happiness and engagement requires rather advanced cognitive skills. Some nursing staff indicated they thus made assessments mostly intuitively, instead of relying on specific observations, thereby reducing the validity of assessments. Additionally, taking into account the values and preferences of the resident for a holistic wellbeing assessment (Gill and Feinstein, 1994) requires extensive knowledge of the resident and careful observations, which may not always be feasible in the time-constrained environment of the nursing home. One way to support this knowledge of nursing staff is by connecting to life stories of residents, an important PCC method that is increasingly implemented in the nursing home environment (Elfrink et al., 2018).

Another possible explanation for the low proxy self-report agreement we found may be related to the fact that the two-week observation period of proxy assessments did not always perfectly overlap with the one-week self-report period in the current study. Although various measurements of nursing home resident QoL use similar time-frames (Hughes et al., 2019), the wellbeing of nursing 
home residents may fluctuate over time (Kolanowski et al., 2007). One could imagine that proxy assessments provided after an engaging game of bingo on Friday may differ considerably from self-reports given on a quiet and lonely Monday. It could thus be that nursing staff merely differed from residents in the kind of moments they had in mind when coming to a wellbeing assessment. Future studies should examine this, e.g. by adopting an experience sampling method (Carstensen et al., 2011) with simultaneous proxy assessments and selfreports. This could be facilitated by incorporating integrated technology (Jensen et al., 2015), such as prompting the happiness and engagement single questions regularly on a device with easy-to-understand 'voting' buttons (e.g. using colours and emojis) - as frequently used in retail outlets.

\section{Limitations}

Besides the above-mentioned limitations of the instrument leaving room for interpretation and the design reducing overlap between assessments and self-reports, the current study had several other strengths and limitations. It is one of the first studies to address proxy assessments of happiness and engagement in the nursing home context with single questions that corresponded closely to resident self-reports. Furthermore, analysing brief motivations helped explain some of the results. Including only residents who do not have dementia for self-reports reduced the issue of low agreement through resident introspective problems (Gerritsen et al., 2007), although it simultaneously limits generalisability. Another limitation is that as data gathering for this study was part of a training programme, nursing staff were free to choose whom to assess, and the number of available proxy assessments varied on care-giver and resident level. More structured and homogeneous data would improve comparability, although results showed that the number of proxy assessments was not related to proxy self-report agreement. Furthermore, nursing staff had only limited time to practise the assessment method, only during training, and continued practice could potentially improve their ability. Finally, this study was conducted in only two (large) nursing homes, and in the Netherlands where care for older adults is relatively well organised and nursing staff are relatively well trained (van der Velden et al., 2011), both limiting generalisability. One can imagine that wellbeing assessments might be even less accurate in other countries with even more profound problems of a fragmented poorly paid workforce and high turnover, but this should be investigated further.

Future studies should pay ample attention to reaching a shared understanding of the concepts, both between colleagues and between nursing staff and residents. Besides, the quality of the relationship between nursing staff and the resident should be investigated as a potential care-giver factor, as residents may express their true feelings more within a good care-giver relationship (Gräske et al., 2012). Furthermore, the exact wording of the single questions and rating options should be a topic of research, because asking residents how happy or satisfied they felt in the previous week may elicit very different answers than asking how good they felt. Others have used satisfactory proxy self-report agreement as a prerequisite during questionnaire development (Bergland et al., 2014), which offers great potential as a basis for single-question measurement development. Finally, 
asking nursing staff to take the perspective of the resident while making the assessment may improve agreement (Leontjevas et al., 2016), suits the subjective character wellbeing and matches PCC practice (Brooker, 2004).

With all this in mind, it should be noted that from a clinical perspective, the variability in proxy assessments may actually be informative. Some care-givers reported specific situations or activities in which they observed happiness and engagement, and combining various observations of several care-givers during team discussions provides in-depth insight into resident preferences. Besides, the difference between care-givers was less than one point on average, which may have only limited clinical significance. A recent study showed that when implementing such a method in practice, it is essential to ensure a stable nursing home context and a clear implementation plan (Kloos et al., 2020).

Still, when taken together, nursing staff did not sufficiently assess happiness and engagement compared to self-reports, differed considerably in their assessments, while the included nursing staff characteristics could not identify which professional care-giver could best provide wellbeing assessments. Accurate regular assessments of resident wellbeing should receive a more prominent place in documentation (Hughes et al., 2019), and using single questions of psycho-social experiences provides potential, but more research is needed. For now, in the absence of any objective measures of wellbeing, and in line with PCC assigning high value on the resident perspective (Brooker, 2004), proxy happiness and engagement assessments should always be combined with regular self-reports whenever possible.

Supplementary material. The supplementary material for this article can be found at https://oi.org/10. 1017/S0144686X20001178.

Acknowledgements. The authors gratefully acknowledge Arnold Driessen for his help in gathering the data and Charlotte van Cleynenbreugel, Sanne Lamers and Jan Voortman for their collaboration and advice in this research project.

Author contributions. All authors made substantial contribution to the conception and design, or analysis and interpretation of the data, drafting the article or revising it, and approval of the published version.

Financial support. This work was supported by the care provider Zorggroep Sint Maarten, Denekamp, The Netherlands, who had no involvement in the study design, in the collection, analysis or interpretation of the data, nor in the decision to submit the article for publication.

Conflict of interest. The authors declare no conflicts of interest.

Ethical standards. The study was approved by the ethics committee of the Faculty of Behavioral, Management and Social Sciences at the University of Twente (number 15016).

\section{References}

Beer C, Flicker L, Horner B, Bretland N, Scherer S, Lautenschlager NT, Schaper F and Almeida OP (2010) Factors associated with self and informant ratings of the quality of life of people with dementia living in care facilities: a cross sectional study. PLOS ONE 5, e15621.

Bergland Å, Kirkevold M, Sandman PO, Hofoss D, Vassbø T and Edvardsson D (2014) Thriving in long-term care facilities: instrument development, correspondence between proxy and residents' self-ratings and internal consistency in the Norwegian version. Journal of Advanced Nursing 70, $1672-1681$. 
Broderick MC and Coffey A (2013) Person-centred care in nursing documentation. International Journal of Older People Nursing 8, 309-318.

Brooker D (2004) What is person-centred care in dementia? Reviews in Clinical Gerontology 13, 215-222.

Bulamu NB, Kaambwa B and Ratcliffe J (2015) A systematic review of instruments for measuring outcomes in economic evaluation within aged care. Health and Quality of Life Outcomes 13, 1-23.

Carstensen LL, Turan B, Scheibe S, Ram N, Ersner-Hershfield H, Samanez-Larkin GR, Brooks KP and Nesselroade JR (2011) Emotional experience improves with age: evidence based on over 10 years of experience sampling. Psychology and Aging 26, 21-33.

Cohen J (1988) Statistical Power Analysis for the Behavioral Sciences, 2nd Edn. Hillsdale, NJ: Lawrence Erlbaum Associates.

Cooper C, Marston L, Barber J, Livingston D, Rapaport P, Higgs P and Livingston G (2018) Do care homes deliver person-centred care? A cross-sectional survey of staff-reported abusive and positive behaviours towards residents from the MARQUE (Managing Agitation and Raising Quality of Life) English national care home survey. PLOS ONE 13, e0193399.

Csikszentmihalyi M, Nakamura J and Abuhamdeh S (2015) Flow. In Csikszentmihalyi M (ed.), Flow and the Foundations of Positive Psychology. Dordrecht, The Netherlands: Springer, pp. 227-239.

Custers AFJ, Westerhof GJ, Kuin Y and Riksen-Walraven M (2010) Need fulfillment in caring relationships: its relation with well-being of residents in somatic nursing homes. Aging er Mental Health 14, 731-739.

Devine A, Taylor SJC, Spencer A, Diaz-Ordaz K, Eldridge S and Underwood M (2014) The agreement between proxy and self-completed EQ-5D for care home residents was better for index scores than individual domains. Journal of Clinical Epidemiology 67, 1035-1043.

Diaz-Redondo A, Rodríguez-Blázquez C, Ayala A, Martinez-Martin P and Forjaz MJ (2014) EQ-5D rated by proxy in institutionalized older adults with dementia: psychometric pros and cons. Geriatrics and Gerontology International 14, 346-353.

Dichter MN, Schwab CGG, Meyer G, Bartholomeyczik S, Dortmann O and Halek M (2014) Measuring the quality of life in mild to very severe dementia: testing the inter-rater and intra-rater reliability of the German version of the QUALIDEM. International Psychogeriatrics 26, 825-836.

Diener E, Emmons RA, Larsen RJ and Griffin S (1985) The satisfaction with life scale. Journal of Personality Assessment 49, 71-75.

Diener E, Suh EM, Lucas RE and Smith HL (1999) Subjective well-being: three decades of progress. Psychological Bulletin 125, 276-302.

Edvardsson D (2015) Notes on person-centered care: what it is, and what it is not. Nordic Journal of Nursing Research 35, 65-66.

Edvardsson D, Winblad B and Sandman P (2008) Person-centred care of people with severe Alzheimer's disease: current status and ways forward. Lancet Neurology 7, 362-367.

Elfrink TR, Zuidema SU, Kunz M and Westerhof GJ (2018) Life story books for people with dementia: a systematic review. International Psychogeriatrics 30, 1797-1811.

Ettema TP, Dröes RM, de Lange J, Mellenbergh GJ and Ribbe MW (2007) QUALIDEM: development and evaluation of a dementia specific quality of life instrument. Scalability, reliability and internal structure. International Journal of Geriatric Psychiatry 22, 549-556.

Gerritsen DL, Steverink N, Ooms ME, De Vet HCW and Ribbe MW (2007) Measurement of overall quality of life in nursing homes through self-report: the role of cognitive impairment. Quality of Life Research 16, 1029-1037.

Gill T and Feinstein A (1994) A critical appraisal of the quality-of-life measurements. Journal of the American Medical Association 272, 619-626.

Gräske J, Fischer T, Kuhlmey A and Wolf-Ostermann K (2012) Quality of life in dementia care - differences in quality of life measurements performed by residents with dementia and by nursing staff. Aging and Mental Health 16, 819-827. ***

Griffiths AW, Kelley R, Garrod L, Perfect D, Robinson O, Shoesmith E, McDermid J, Burnley N and Surr CA (2019) Barriers and facilitators to implementing dementia care mapping in care homes: results from the DCM ${ }^{\mathrm{TM}}$ EPIC trial process evaluation. BMC Geriatrics 19, 37.

Griffiths AW, Smith SJ, Martin A, Meads D, Kelley R and Surr CA (2020) Exploring self-report and proxy-report quality-of-life measures for people living with dementia in care homes. Quality of Life Research 29, 463-472. 
Hayes AF and Krippendorff K (2007) Answering the call for a standard reliability measure for coding data. Communication Methods and Measures 1, 77-89.

Hounsome N, Orrell M and Edwards RT (2011) EQ-5D as a quality of life measure in people with dementia and their carers: evidence and key issues. Value in Health 14, 390-399.

Hughes LJ, Farina N, Page TE, Tabet N and Banerjee S (2019) Psychometric properties and feasibility of use of dementia specific quality of life instruments for use in care settings: a systematic review. International Psychogeriatrics, 1-15. doi:10.1017/s1041610218002259.

Irving K, Treacy M, Scott A, Hyde A, Butler M and MacNeela P (2006) Discursive practices in the documentation of patient assessments. Journal of Advanced Nursing 53, 151-159.

Jensen RE, Rothrock NE, Dewitt EM, Spiegel B, Tucker CA, Crane HM, Forrest CB, Patrick DL, Fredericksen R, Shulman LM, Cella D and Crane PK (2015) The role of technical advances in the adoption and integration of patient-reported outcomes in clinical care. Medical Care 53, 153-159.

Jongenelis K, Gerritsen DL, Pot AM, Beekman ATF, Eisses AMH, Kluiter H and Ribbe MW (2007) Construction and validation of a patient- and user-friendly nursing home version of the Geriatric Depression Scale. International Journal of Geriatric Psychiatry 22, 837-842.

Kane RL, Kane RA, Bershadsky B, Degenholtz H, Kling K, Totten A and Jung K (2005) Proxy sources for information on nursing home residents' quality of life. Journals of Gerontology: Psychological Sciences and Social Sciences 60B, 318-325.

Katz S, Ford AB, Moskowitz RW, Jackson BA and Jaffe MW (1963) Studies of illness in the aged: the Index of ADL: a standardized measure of biological and psychosocial function. Journal of the American Medical Association 185, 914-919.

Keyes CLM (2002) The mental health continuum: from languishing to flourishing in life. Journal of Health and Social Behavior 43, 207-222.

Kloos N, Drossaert CHC, Trompetter HR, Bohlmeijer ET and Westerhof GJ (2020) Exploring facilitators and barriers to using a person centered care intervention in a nursing home setting. Geriatric Nursing, in press. https://doi.org/10.1016/j.gerinurse.2020.04.018

Kolanowski A, Hoffman L and Hofer SM (2007) Concordance of self-report and informant assessment of emotional well-being in nursing home residents with dementia. Journals of Gerontology: Psychological Sciences and Social Sciences 62B, 20-27.

Koo TK and Li MY (2016) A guideline of selecting and reporting intraclass correlation coefficients for reliability research. Journal of Chiropractic Medicine 15, 155-163.

Koren MJ (2010) Person-centered care for nursing home residents: the culture-change movement. Health Affairs 29, 312-317.

Kottner J and Dassen T (2008) An interrater reliability study of the Braden scale in two nursing homes. International Journal of Nursing Studies 45, 1501-1511.

Laevers F (2005) Well-being and Involvement in Care Settings. A Process-oriented Self-evaluation Instrument. Leuven, Belgium: Research Centre for Experiential Education, Leuven University. Available at https://www.kindengezin.be/img/cisc-ziko-manual.pdf.

Leontjevas R, Teerenstra S, Smalbrugge M, Koopmans RTCM and Gerritsen DL (2016) Quality of life assessments in nursing homes revealed a tendency of proxies to moderate patients' self-reports. Journal of Clinical Epidemiology 80, 123-133.

McCormack B and McCance TV (2010) Person-centred Nursing: Theory and Practice. Oxford: Wiley-Blackwell.

Murtagh FEM, Ramsenthaler C, Firth A, Groeneveld EI, Lovell N, Simon ST, Denzel J, Guo P, Bernhardt F, Schildmann E, van Oorschot B, Hodiamont F, Streitwieser S, Higginson IJ and Bausewein C (2019) A brief, patient- and proxy-reported outcome measure in advanced illness: validity, reliability and responsiveness of the Integrated Palliative care Outcome Scale (IPOS). Palliative Medicine 33, 1045-1057.

Pavot W and Diener E (1993) Review of the satisfaction with life scale. Psychological Assessment 5, 164-172.

Rathert C, Wyrwich MD and Boren SA (2013) Patient-centered care and outcomes: a systematic review of the literature. Medical Care Research and Review 70, 351-379.

Robertson S, Cooper C, Hoe J, Hamilton O, Stringer A and Livingston G (2017) Proxy rated quality of life of care home residents with dementia: a systematic review. International Psychogeriatrics 29, 569-581. 
Robertson S, Cooper C, Hoe J, Lord K, Rapaport P, Marston L, Cousins S, Lyketsos CG and Livingston G (2020) Comparing proxy rated quality of life of people living with dementia in care homes. Psychological Medicine 50, 86-95.

Ryan RM and Deci EL (2001) On happiness and human potentals: a review of research on hedonic and eudaimonic well being. Annual Review of Psychology 52, 141-166.

Schneider L and Schimmack U (2009) Self-informant agreement in well-being ratings: a meta-analysis. Social Indicators Research 94, 363-376.

Spector A and Orrell M (2006) Quality of Life (QoL) in dementia: a comparison of the perceptions of people with dementia and care staff in residential homes. Alzheimer's Disease \& Associated Disorders 20, $160-165$.

Ullén F, de Manzano Ö, Almeida R, Magnusson PKE, Pedersen NL, Nakamura J, Csikszentmihalyi M and Madison G (2012) Proneness for psychological flow in everyday life: associations with personality and intelligence. Personality and Individual Differences 52, 167-172.

Usman A, Lewis S, Hinsliff-Smith K, Long A, Housley G, Jordan J, Gage H, Denning T, Gladman JRF and Gordon AL (2019) Measuring health-related quality of life of care home residents: comparison of self-report with staff proxy responses. Age and Ageing 48, 407-413.

van der Velden LFJ, Francke AL and Batenburg RS (2011) Vraag-en aanbodontwikkelingen in de verpleging en verzorging in Nederland [Supply and Demand Developments in Nursing and Care in the Netherlands]. Available at http://www.nivel.nl/sites/default/files/bestanden/Zelfmanagement_wat_betekent_ het_voor_het_patient.pdf\%5Cnpapers3://publication/uuid/27382F86-43E4-4649-8AEC-C809A4E169DE.

Veenhoven R (2008) Effects of happiness on physical health and the consequences for preventive health care. Happiness Studies 9, 1-26.

Westerhof GJ, Miche M, Brothers AF, Barrett AE, Diehl M, Montepare JM, Wahl HW and Wurm S (2014) The influence of subjective aging on health and longevity: a meta-analysis of longitudinal data. Psychology and Aging 29, 793-802.

Cite this article: Kloos N, Drossaert CHC, Bohlmeijer ET, Westerhof GJ (2022). How well do nursing staff assess the wellbeing of nursing home residents? An explorative study of using single-question scales. Ageing \& Society 42, 812-828. https://doi.org/10.1017/S0144686X20001178 